\title{
WALTER BENJAMIN E O "REAL ESTADO DE EXCEÇÃO”: UMA INTERPRETAÇÃO ACERCA DA TESE VIII DE SOBRE O CONCEITO DE HISTÓRIA
}

Nathan Ramos Vieira

\begin{abstract}
RESUMO
O presente artigo tem como objetivo realizar uma leitura crítica acerca da tese VIII de Sobre o conceito de história sob a perspectivas das ideias expostas por Walter Benjamin em Para uma crítica da violência e por Carl Schmitt em Teologia política. 0 elo entre as obras de Benjamin e Schmitt será a perspectiva de Agamben, segundo a qual, Teologia política seria uma resposta à Crítica da violência, permitindo uma melhor compreensão acerca da exceção e de como essa se vincula ao Direito. Após uma exposição das ideias apresentadas por Benjamin e Schmitt, ao retomar a leitura da tese VIII se evidenciará o significado do "real estado de exceção" citado por Benjamin, que faz referência à violência divina citada na Crítica da violência, a saber, de superar o movimento dialético entre violência instauradora e violência mantenedora do direito, cuja ruptura se dará através da greve geral proletária e da aniquilação do poder do Estado.
\end{abstract}

Palavras-chave: Walter Benjamin. Carl Schmitt. Sobre o conceito de história. Para uma crítica da violência. Teologia política.

WALTER BENJAMIN AND THE "REAL STATE OF EXCEPTION": AN INTERPRETATION ABOUT THE THESIS VIII ON THE CONCEPT OF HISTORY

\begin{abstract}
This article aims to carry out a critical reading about the thesis VIII of On the concept of history under the perspective of the ideas exposed by Walter Benjamin in Critique of violence and by Carl Schmitt in Political theology. The link between the Works of Benjamin and Schmitt will be Agamben's view that Political theology would be a response to the Critique of violence, allowing a better understanding of the exception and how it relates to law. After an exposion of the ideas presented by Benjamin and Schmitt, resuming the reading of the thesis VIII will reveal the meaning of the "real state of exception" cited by Benjamin, which refers to the divine violence cited in the Critique of violence, the dialectical movement between lawmaking and law-preserving violence, whose rupture will occur through the proletarian general strike and the annihilation of state power.
\end{abstract}

Keywords: Walter Benjamin. Carl Schmitt. On the concept of history. Critique of violence. Political theology. 


\section{Introdução}

O presente artigo tem como objetivo efetuar uma interpretação da tese VIII de Sobre o conceito de história, partindo das relações tecidas por Agamben entre os textos: Para uma crítica da violência, de Walter Benjamin, e Teologia política, de Carl Schmitt.

Para tal interpretação, primeiramente será apresentada a tese VIII juntamente de uma exposição acerca das relações traçadas por Agamben entre os textos de Benjamin e Schmitt, abordando a questão relativa à exceção e sua vinculação com a soberania. Neste ponto, apresentar-se-á o ensaio de Benjamin, Para uma crítica da violência, visando oferecer uma noção acerca da oposição entre a violência mítica e a violência divina; o movimento dialético entre a violência instauradora do direito e a violência mantenedora do direito; assim como, a posição de Benjamin referente à possibilidade de uma forma de violência pura.

Em sequência, será apresentada a Teologia política de Schmitt, tendo como foco as ideias expostas em seu primeiro capítulo, concernentes a soberania e ao estado de exceção, apresentando a relação estabelecida entre exceção e soberania. Posteriormente, retornando a Agamben e a constatação compartilhada por esse com Benjamin na tese VIII, de que o estado de exceção teria se tornado a regra. Prosseguindo, efetuar-se-á uma leitura crítica da tese VIII, tendo em vista as ideias expostas em Para uma crítica da violência e Teologia política, juntamente com os posicionamentos de Agamben, visando oferecer uma resposta acerca do "real estado de exceção" evocado por Benjamin na tese VIII.

\section{Tese VIII, estado de exceção e as relações entre Benjamin e Schmitt}

Benjamin aborda o tema do estado de exceção na tese VIII ao constatar que esse teria se tornado regra e que, da necessidade em se encontrar um conceito de história capaz de abarcar tal situação, sendo que deste, surgirá a tarefa de se instaurar um real estado de exceção, no qual a luta contra o fascismo se dará em melhor condição. De tal forma, Benjamin redige a tese VIII da seguinte maneira: 


\begin{abstract}
A tradição dos oprimidos nos ensina que o 'estado de exceção' no qual vivemos é a regra. Precisamos chegar a um conceito de história que dê conta disso. Então surgirá diante de nós nossa tarefa, a de instaurar o real estado de exceção; e graças a isso, nossa posição na luta contra o fascismo tornarse-á melhor. A chance deste consiste, não por último, em que seus adversários o afrontem em nome do progresso como se este fosse uma norma histórica. - $\mathrm{O}$ espanto em constatar que os acontecimentos que vivemos 'ainda' sejam possíveis no século $X X$ não é nenhum espanto filosófico. Ele não está no início de um conhecimento, a menos que seja o de mostrar que a representação da história donde provém aquele espanto é insustentável. (BENJAMIN, 2005, 83).
\end{abstract}

Conforme a interpretação de Löwy $(2005,83)$, Benjamin teria se influenciado pelas ideias expostas por Schmitt em Teologia política, em especial a noção de soberania, a qual é relacionada com o estado de exceção, onde, nas palavras de Schmitt: "Soberano é aquele que decide na exceção" (SCHMITT, 2005, 5). Em contrapartida, ao tomarmos como válida a interpretação de Agamben, a relação entre o pensamento de Benjamin e Schmitt teria se iniciado antes da redação das teses sobre O conceito de história. Para Agamben (2005, 52-3), antes de Benjamin ter obtido contato com a Teologia política de Schmitt, o jurista alemão teria tido contato com o ensaio Para a crítica da violência, de autoria de Benjamin, publicado na edição 47 do Archiv für Sozialwissenschaften und Sozialpolitik, onde Schimitt veio a publicar ensaios e artigos, além de ter sido um leitor regular. Na opinião de Agamben seria muito difícil que Schmitt deixasse passar sem ler um texto como Para a crítica da violência ${ }^{1}$.

Segundo Agamben $(2005,54)$, a teoria da soberania desenvolvida por Schmitt em Teologia política pode ser lida como uma resposta ao ensaio de Benjamin. A estratégia adotada por Benjamin na Crítica da violência é buscar garantir a existência de uma forma de violência pura e anômica, em contrapartida, Schmitt busca conduzir tal violência novamente a um contexto jurídico, de forma que a anomia seria um sintoma interno ao nomos jurídico². Para Schmitt não há a possibilidade da existência

\footnotetext{
${ }^{1}$ Agamben reforça a tese de que Schmitt teria tomado conhecimento do ensaio de Benjamin antes que este tivesse lido a Teologia política ao afirmar que: "Em 1920, enquanto trabalhava na redação da Crítica, com toda probabilidade Benjamin ainda não havia lido aquela Politische Theologie, cuja definição da soberania citaria cinco anos após no livro sobre o drama barroco; [...]" (AGAMBEN, 2010, $69)$.

2 Agamben descreve o movimento no qual Schmitt busca conduzir a "violência pura" para dentro do estatuto jurídico previsto da seguinte forma: "O estado de exceção é o espaço em que ele tenta capturar a ideia de Benjamin de uma violência pura e inscrever a anomia dentro do próprio corpo do nomos." (AGAMBEN, 2005, 54).

Doutorando em Filosofia pela Universidade Federal do Rio de Janeiro (UFRJ). Brasileiro, residente no Rio de Janeiro - RJ. E-mail: nvieira1991@gmail.com
} 
de uma violência pura - isto é, de uma violência que seja externa ao Direito - pois, no estado de exceção, esta violência dita pura estaria incluída na lei através de sua própria exclusão ${ }^{3}$, isto é: $O$ estado de exceção é o dispositivo pelo qual Schmitt responde à afirmação de Benjamin acerca de uma ação humana totalmente anômica, tendo em vista que a situação de exceção já se encontra prevista na Constituição. A violência soberana, expressa por Schmitt na Teologia política, corresponderia a violência pura descrita no ensaio de Benjamin, uma figura de poder que não cria e/ou preserva a lei, mas que a suspende.

Acerca da relação entre a Teologia política e a Crítica da violência, Agamben conclui que:

\begin{abstract}
A relação entre esses dois textos, no entanto, é ainda mais próxima do que isso. Vimos como, na Teologia Política Schmitt abandona a distinção entre poder constituinte e poder constituído, que no livro de 1921 fundou a ditadura soberana e a substitui pelo conceito de decisão. Essa substituição adquire seu sentido estratégico apenas quando vista como contra-ataque em resposta à crítica de Benjamin. Pois a distinção entre a violência que legisla e a violência que preserva a lei - que era o alvo de Benjamin - corresponde a carta à oposição de Schmitt, e é para neutralizar essa nova figura de uma violência pura, removida da dialética entre o poder constituinte e o poder constituído onde Schmitt vem a desenvolver sua teoria da soberania. (AGAMBEN, 2005, 54).
\end{abstract}

\title{
2 Para a crítica da violência e as oposições entre as distintas formas de violência
}

Em Para a crítica da violência Benjamin busca delimitar os diferentes domínios em que Gewalt (violência/poder) se exerce, buscando refletir acerca da oposição entre o "poder-como-violência" do Direito e do Estado, e a "violência-comopoder", forma que se mostra no caso da greve revolucionária. O título em alemão Zur Kritik der Gewalt exibe o caráter dúbio da violência que Benjamin visa explicitar no ensaio, onde "Gewalt" pode significar tanto "poder" quanto "violência", enquanto que o conceito de "Kritik" é empregado por Benjamin na forma de uma crítica, mas com caráter de "delimitação de limites", onde:

\footnotetext{
${ }^{3}$ Para Schmitt, o ato de estipular que tal forma de violência esteja excluída do Direito teria como origem um ato que se deu dentro do ordenamento jurídico, de forma que tal violência pura continua vinculada ao Direito pois sua exclusão - a definição de que esta é externa ao Direito - se deu por intermédio do ordenamento jurídico.

Doutorando em Filosofia pela Universidade Federal do Rio de Janeiro (UFRJ). Brasileiro, residente no Rio de Janeiro - RJ. E-mail: nvieira1991@gmail.com
} 
A tarefa de uma crítica da violência pode se circunscrever à apresentação de suas relações com o direito e com a justiça. Pois, qualquer que seja o modo como atua uma causa, ela só se transforma em violência, no sentido pregnante da palavra, quando interfere em relações éticas. (BENJAMIN, 2013, 121).

Benjamin inicia por analisar o uso da violência na esfera dos meios, podendo esta ser destinada a fins justos ou injustos. Tem-se então a diferenciação entre o direito natural e o direito positivo. Enquanto o direito natural se preocuparia tão somente com os fins - caso os fins sejam justos então os meios (mesmo com o emprego de violência) são aceitáveis -, o direito positivo se pergunta se determinados meios são passíveis de justificativa para determinado fim. Neste ponto, diz Benjamin que: "[...], pois, se o direito positivo é cego para o caráter incondicional dos fins, então o direito natural o é para o caráter condicional dos meios." (BENJAMIN, 2013, 124).

Prosseguindo no ensaio de Benjamin, é constatado que no direito positivo haveria uma diferenciação entre dois tipos de violência, a saber: violência sancionada e violência não sancionada, cuja diferenciação se deve à existência ou não de reconhecimento histórico. A violência sancionada é uma violência que conta com a existência de reconhecimento histórico e que se destina a fins naturais, enquanto que a violência não sancionada é uma forma de violência desprovida de reconhecimento histórico e destinada a fins de direito, donde resultaria a seguinte máxima relativa à Europa: "Pode-se formular como máxima geral da legislação europeia atual o seguinte: todos os fins naturais dos indivíduos devem colidir com fins de direito, quando perseguidos com maior ou menor violência." (BENJAMIN, 2013, 126).

Benjamin prossegue e dá espaço à diferenciação entre a violência instauradora do direito (aquela que funda uma ordem de direito) e a violência mantenedora do direito (responsável pela preservação de uma ordem de direito). Dentre os exemplos apresentados talvez o que tenha causado maior choque em Benjamin tenha sido a polícia, pois esta encarna em sua figura tanto a violência mantenedora quanto a violência instauradora do direito. Da violência instauradora do direito exige-se a comprovação de sua aplicação através da vitória ${ }^{4}$, enquanto que da violência

\footnotetext{
4 Um dos exemplos dados por Benjamin seria a guerra, na qual a nação derrotada reconhece os termos impostos pelo lado vencedor através da assinatura de um tratado de paz. O tratado de paz aqui seria a comprovação da aplicação da violência instauradora do Direito, a qual se deu através da vitória na guerra.

Doutorando em Filosofia pela Universidade Federal do Rio de Janeiro (UFRJ). Brasileiro, residente no Rio de Janeiro - RJ. E-mail: nvieira1991@gmail.com
} 
mantenedora do direito exige-se a restrição de não se propor a novos fins, entretanto, a polícia é uma instituição isenta destes dois requisitos, de forma que, nas palavras de Benjamin:

Ela é instauradora do direito - com efeito, sua função característica, sem dúvida, não é a promulgação de leis, mas a emissão de decretos de todo tipo, que ela afirma com pretensão de direito - e é mantenedora do direito, uma vez que se coloca à disposição de tais fins. (BENJAMIN, 2013, 135).

Toda violência como meio é ou instauradora ou mantenedora do direito, caso a violência não seja capaz de reivindicar um destes pressupostos ela renuncia à sua validade. Neste quadro, o "Direito" da polícia mostra o ponto no qual o Estado não mais é capaz de garantir - através da ordem de direito - os fins que busca alcançar:

\begin{abstract}
Por isso a polícia intervém 'por razões de segurança' em um número incontável de casos nos quais não há nenhuma situação de direito clara, para não falar nos casos em que, sem qualquer relação com fins de direito, ela acompanha o cidadão como uma presença que molesta brutalmente ao longo de uma vida regulamentada por decretos, ou pura e simplesmente o vigia. (BENJAMIN, 2013, 136).
\end{abstract}

Prosseguindo ao longo dos exemplos apresentados por Benjamin, chega-se a diferenciação entre dois tipos de violência: a violência mítica e a violência divina. Benjamin destaca que no caso do homem a cólera o leva a explosões de violência que não possuem relação como meio a determinado fim, de forma que a violência da cólera não constitui um meio, mas sim uma manifestação. Este tipo da manifestação típica da cólera manifesta-se de forma mais significativa no mito, no que diz Benjamin: "A violência mítica em sua forma arquetípica é mera manifestação dos deuses. Não meio para seus fins, dificilmente manifestação de sua vontade; em primeiro lugar, manifestação de sua existência." (BENJAMIN, 2013, 147). Essa forma de violência apresenta-se mais como instauração de um direito do que punição à violação de um direito pré-existente ${ }^{5}$.

Ao se questionar acerca da existência de uma violência pura, capaz de se contrapor à violência mítica, Benjamin diz que: "Assim como em todos os domínios Deus se opõe ao mito, a violência divina se opõe à violência mítica." (BENJAMIN,

\footnotetext{
${ }^{5}$ Benjamin cita como exemplo a lenda de Níobe, de forma que a violência instauradora do direito se revela como uma forma de garantir o poder.

Doutorando em Filosofia pela Universidade Federal do Rio de Janeiro (UFRJ). Brasileiro, residente no Rio de Janeiro - RJ. E-mail: nvieira1991@gmail.com
} 
2013, 150). A violência mítica é instauradora do direito, estabelece fronteiras, traz de forma simultânea culpa e expiação, é ameaçadora e sangrenta, em contrapartida, a violência divina é aniquiladora do direito, não estabelece fronteiras e aniquila sem limites, expia a culpa e golpeia sem ameaças, além de ser letal de uma maneira nãosangrenta. A aniquilação da violência divina expia a culpa e, segundo Benjamin, existe uma conexão entre o caráter não-sangrento e o caráter de expiação purificadora que esta violência possui. A expiação livraria o culpado não apenas de sua culpa, mas também do Direito, no que diz Benjamin:

Pois com a mera vida termina o domínio sobre o vivente. A violência mítica é violência sangrenta exercida, em favor próprio, contra a mera vida; a violência divina pura se exerce contra toda a vida, em favor do vivente. A primeira exige sacrifícios, a segunda os aceita. (BENJAMIN, 2013, 151-2).

Existe a presença de um movimento dialético de altos e baixos entre as violências instauradora e mantenedora do direito. Uma violência instaura um Direito e o mantém (torna-se uma violência mantenedora) até o momento em que esse Direito é solapado por uma violência - também instauradora - anteriormente suprimida, mas que agora instaura um novo Direito e passa a mantê-lo. Desta forma, se mantém um ciclo de ascensão e queda entre essas formas de violência que são relacionadas às formas míticas do Direito, no que diz Benjamin: "É na ruptura desse círculo atado magicamente nas formas míticas do direito, na destituição do direito e de todas as violências das quais ele depende, e que dependem dele, em última instância, então, na destituição da violência do Estado que se funda uma nova era histórica." (BENJAMIN, 2013, 155).

Benjamin diz que as formas de violência mítica devem ser rejeitadas, ou seja, deve-se rejeitar a violência instauradora do direito - que é violência arbitrária - assim como a violência mantenedora do direito - que é violência administrada e se encontra à serviço da violência instauradora do direito. Quanto à violência divina, Benjamin conclui seu ensaio dizendo:

\footnotetext{
Mas toda violência mítica, instauradora do direito, que é lícito chamar de 'violência arbitrária' [schaltende Gewalt], deve ser rejeitada. É preciso rejeitar também a violência mantenedora do direito, a 'violência administrada' [verwaltete Gewalt], que está a serviço da primeira. A violência divina, que é insígnia e selo, nunca meio de execução sagrada, pode ser chamada de 'violência que reina' [waltende Gewalt]. (BENJAMIN, 2013, 156).
} 


\section{Teologia política e a relação entre soberania e exceção}

A obra de Schmitt dedica-se a analisar a natureza e as prerrogativas da autoridade política soberana, onde sua primeira frase enuncia: "Soberano é aquele que decide na exceção" (SCHMITT, 2005, 5). Na visão de Schmitt apenas esta definição é capaz de fazer jus a um conceito tão limítrofe, sem que se caia em imprecisões terminológicas. Schmitt ressalta que essa definição de soberania deve ser associada a uma situação excepcional, e não a casos rotineiros, onde: "Logo se tornará claro que a exceção deve ser compreendida em referência à um conceito geral na teoria do Estado, e não meramente como um constructo aplicado a cada decreto emergencial ou estado de sítio." (SCHMITT, 2005, 5).

Segundo Schmitt $(2005,5-7)$, a asserção de que a exceção é verdadeiramente apropriada para a definição jurídica de soberania possui uma fundamentação lógicolegal. A decisão na exceção é a que possui senso real no mundo, pois uma norma geral - a qual possuiria o caráter de uma prescrição legal - é incapaz de abranger um caso de exceção total, a decisão de que uma exceção real existe também não pode ser derivada de uma norma. Na visão de Schmitt é precisamente a exceção que torna relevante a questão da soberania, isto se deve ao fato de que os detalhes de uma situação de emergência não podem ser antecipados na legislação destinada à situação de normalidade. A melhor orientação que uma constituição pode oferecer na perspectiva de Schmitt - é indicar quem será responsável por agir e tomar as decisões necessárias em situação de exceção e como superá-la.

No caso de uma situação de exceção a Constituição vigente deve ser suspensa, o soberano (aquele apontado no texto constitucional como responsável pelas decisões em um estado de emergência) deve agir livremente, visando a superação da situação excepcional, de forma a propiciar um quadro de normalidade no qual a Constituição possa voltar a ter sua validade e aplicabilidade. Nas palavras de Schmitt:

O que caracteriza uma exceção é principalmente a autoridade ilimitada, o que significa a suspensão de toda a ordem existente. Em tal situação é claro que - Estado permanece, enquanto que a Lei recua. Porque a exceção é diferente Doutorando em Filosofia pela Universidade Federal do Rio de Janeiro (UFRJ). Brasileiro, residente no Rio de Janeiro - RJ. E-mail: nvieira1991@gmail.com 
da anarquia e do caos, a ordem no senso jurídico ainda prevalece mesmo não sendo do tipo ordinário. (SCHMITT, 2005, 12).

A exceção é diferenciada da anarquia e do caos, pois nestas situações ocorre uma abolição do sistema legal vigente, enquanto que na exceção o sistema legal é apenas suspenso (dado sua incapacidade de operar em uma situação excepcional, que fuja da normalidade para a qual tal Constituição foi redigida), cabendo ao soberano tomar as medidas necessárias para o reestabelecimento de um estado de normalidade no qual tal sistema legal suspenso possa voltar a vigorar. Para Schmitt a exceção mostra-se mais interessante do que a norma. A norma não provaria nada, enquanto a exceção prova tudo, o que confirmaria que, não apenas a norma em si, mas sua existência é derivada da exceção, de forma que: "Na exceção o poder da vida real rompe a crosta de um mecanismo que se tornou torpe pela repetição" (SCHMITT, 2005, 15).

\section{Agamben e o paralelo entre soberania e exceção}

Para Agamben $(2005,33)$, a contribuição da teoria de Schmitt teria sido possibilitar a articulação entre a ordem jurídica e o estado de exceção. A exceção representa uma exclusão, um caso singular que é excluído da norma geral de determinado Estado, nesta medida, Agamben diz que: "O estado de exceção não é, portanto, o caos que precede a ordem, mas a situação que resulta da sua suspensão." (AGAMBEN, 2010, 24). Agamben também ressalta que um dos elementos que tornam difícil uma definição acerca do estado de exceção seria a relação próxima deste com a guerra civil, insurreição e resistência, pois estas também se apresentam como uma zona de indecidibilidade, oposta ao estado de normalidade.

Entretanto, acerca da relação entre a exceção e a soberania, diz Agamben que:

A exceção que define a estrutura da soberania é, porém, ainda mais complexa. Aquilo que está fora vem aqui incluído não simplesmente através de uma interdição ou de um internamento, mas suspendendo a validade do ordenamento, deixando, portanto, que ele se retire da exceção, a abandone. Não é a exceção que se subtrai à regra, mas a regra que, suspendendo-se, dá lugar à exceção e somente deste modo se constitui como regra, mantendo-se em relação com aquela. (AGAMBEN, 2010, 25).

Doutorando em Filosofia pela Universidade Federal do Rio de Janeiro (UFRJ). Brasileiro, residente no Rio de Janeiro - RJ. E-mail: nvieira1991@gmail.com 
Uma das constatações de Agamben é que a emergência - a exceção - tem se tornado a regra. $\mathrm{O}$ estado de exceção tornou-se o padrão vigente, onde:

\begin{abstract}
Diante da irrefreável progressão do que se tem chamado de 'guerra civil global', o estado de exceção tende a aparecer cada vez mais como o paradigma dominante do governo na política contemporânea. Essa transformação de uma medida provisória e excepcional em uma técnica de governo que ameaça alterar radicalmente - na verdade, já alterou palpavelmente - a estrutura e o significado da distinção tradicional entre formas constitucionais. (AGAMBEN, 2005, 2).
\end{abstract}

As sociedades contemporâneas vivem em estados de exceção constantes, que se tornam a regra geral, suprimindo direitos civis, políticos e sociais dos indivíduos através da aplicação da violência e da emissão de decretos, por parte do Estado, visando a manutenção do poder. Agamben considera que a decisão do soberano não se trata simplesmente da vontade expressa de um indivíduo superior aos demais em uma escala hierárquica, ela trata, acerca da implicação do ser vivente no Direito, da estruturação das relações de vida requeridas pela legislação de determinado território.

\title{
5 A Tese VIII e o "real estado de exceção"
}

A primeira constatação de Benjamin na tese VIII é a de que o estado de exceção se tornou a regra. Essa constatação também é defendida por Agamben (2010, 26-7), em nosso tempo cada vez mais o estado de exceção emerge ao primeiro plano, substituindo a normalidade (e consequentemente, a Constituição responsável por "decidir" na normalidade - o que estaria em acordo com a exposição de Schmitt acerca da exceção) e se tornando regra, deste modo, abrindo espaço para a adoção de medidas que não estavam previstas na Constituição em nome de tal estado de exceção.

Ao dizer que está diante de nós a tarefa de instaurar o "real estado de exceção" (BENJAMIN, 2005, 83) e que desta ação resultaria uma melhora no quadro da luta contra o fascismo, Benjamin traz à tona a disparidade entre a violência mítica e a violência divina expressa na Crítica da violência. O fascismo instaurado na Europa no 
período em que Benjamin redigiu as Teses foi mais uma etapa do ciclo, do movimento dialético, entre a violência instauradora e a violência mantenedora do direito, entretanto, este se utilizou de um aparato não descrito por Benjamin neste movimento dialético, a saber: o estado de exceção.

Ao tomar o poder o fascismo utiliza-se da violência instauradora do direito, não da forma descrita por Benjamin na Crítica da violência (suprimindo a ordem vigente e fundando uma nova ordem de direito), mas sim proclamando o estado de exceção, que ao suspender a constituição vigente de um Estado se utiliza da violência mantenedora do direito, através da emissão de decretos emergenciais, assegurando sua estada no poder. Diferentemente também da exposição de Schmitt, o soberano neste "estado de exceção fascista" não busca restaurar uma situação de normalidade através de medidas emergenciais visando que a constituição suspensa possa se tornar novamente válida e aplicável, pelo contrário, no estado de exceção fascista as medidas emergenciais visam apenas a manutenção do poder, sem qualquer compromisso de tornar a normalidade novamente a regra.

O estado de exceção fascista opera tal qual a polícia (na descrição feita por Benjamin na Crítica), instaurando Direito através de seus decretos emitidos sob a prerrogativa do estado de exceção, e mantendo esse direito, onde se utiliza de todos os meios para reprimir seus adversários e assegurar seu local de poder. Um exemplo prático foi o Estado nazista, o qual, com a chegada de Hitler ao poder em 1933, suspendeu a Constituição de Weimar, governando a partir de decretos com força de lei emitidos pelo Führer, sem a preocupação em reestabelecer a situação de normalidade e a Constituição suspensa - ou de até mesmo redigir uma nova Constituição. No caso alemão o país voltou a ter um texto constitucional vigente apenas no pós-guerra.

O "real estado de exceção" remete à violência divina, a uma violência tal qual aquela pensada por Benjamin na greve geral proletária. Faz-se necessária a quebra do movimento dialético entre violência instauradora e violência mantenedora do direito, descrito por Benjamin na Crítica da violência:

É na ruptura desse círculo atado magicamente nas formas míticas do direito, na destituição do direito e de todas as violências das quais ele depende, e que dependem dele, em última instância, então, na destituição da violência do Estado que se funda uma nova era histórica. (BENJAMIN, 2013, 155). 
Esse "real estado de exceção", responsável pela quebra do movimento dialético não seria papel dos partidos políticos. Na Crítica da violência os parlamentos são apresentados como uma instituição que teria se esquecido das forças revolucionárias às quais deve sua existência. Estariam desprovidos de consciência acerca da violência instauradora do Direito que neles está representada. Nas palavras de Benjamim:

É significativo que a deterioração dos parlamentos tenha afastado do ideal de um aplainar não-violento dos conflitos políticos um número tão grande de pessoas quanto a guerra havia conduzido a esse ideal. Aos pacifistas opõemse os bolcheviques e os sindicalistas. Eles fizeram uma crítica arrasadora e, no seu todo, acertada dos parlamentos atuais. Por desejável e satisfatório que possa ser, comparativamente, um parlamento de alto nível, a discussão dos meios, por princípio não violentos, de entendimento político não poderá incluir o parlamentarismo. Pois o que este consegue alcançar em questões vitais só podem ser aquelas ordenações do direito que têm a marca da violência tanto na origem como no desfecho. (BENJAMIN, 2013, 138).

O "real estado de exceção" teria sua efetivação através da classe operária, mas cabe dizer que Benjamin aponta uma diferenciação entre duas modalidades de greve e uma oposição no referente a violência correspondente a cada uma destas. A greve geral política teria como base o fortalecimento do poder estatal, de suas organizações, onde os políticos (socialistas moderados) instaurariam um poder forte e centralizado. Este tipo de greve demonstra como o Estado não perderia nada de sua força, o poder apenas seria transferido para as mãos de um grupo político diferente, de privilegiados a privilegiados, e não para a classe proletária, perpetuando assim o movimento dialético entre violência instauradora e violência mantenedora do direito. Em contraposição à greve geral política, a greve geral proletária propõe-se a aniquilação do poder do Estado. Ela enxerga o Estado como a "razão de ser" dos grupos dominantes, responsáveis por tirar proveito dos meios de produção, dessa forma, conforme Benjamin:

Enquanto a primeira forma de suspensão do trabalho é violenta, uma vez que provoca só uma modificação exterior das condições de trabalho, a segunda, enquanto meio puro, é não-violenta. Com efeito, esta não acontece com a disposição de retomar o trabalho depois de concessões superficiais ou de qualquer modificação das condições de trabalho, mas com a resolução de retomar apenas um trabalho totalmente transformado, sem coerção por parte do Estado, uma subversão que esse tipo de greve não apenas desencadeia, mas leva a sua completude. Por isso, a primeira modalidade de greve é instauradora do direito, a segunda, anarquista. (BENJAMIN, 2013, 143). 
À greve geral proletária é negada qualquer utopia ou programa, assim, negase a possibilidade de instauração de qualquer forma de direito, rompendo com o movimento dialético tal qual a violência divina, gerando assim um "real estado de exceção", onde Estado, Direito e soberano deixam de existir, configurando assim uma violência pura.

\section{CONCLUSÃO}

$\mathrm{Na}$ tese VIII Benjamin aborda a questão do estado de exceção, constatando que esse tornou-se a regra, a situação de normalidade deu lugar a um estado de exceção permanente. Ao se encontrar um conceito de história capaz de lidar com a situação em questão, surgirá a tarefa de instaurar o "real estado de exceção", no qual a luta contra o fascismo se dará em melhor condição. Para Löwy, a tese VIII evidencia o confronto entre duas concepções de história, uma progressista e a que representa o ponto de vista da tradição dos oprimidos. Para a primeira, o progresso representaria a evolução democrática das sociedades, enquanto que, para a segunda, este mesmo progresso é representante do discurso dos vencedores, que silencia a violência e a barbárie cometida pelos vencedores contra os oprimidos.

Outra questão levantada por Benjamin refere-se a um espanto em que os acontecimentos em questão - a ascensão do fascismo e o estado de exceção como regra - ainda sejam possíveis no século XX. Esse espanto não é um espanto filosófico, ele provém de uma representação histórica que, segundo Benjamin, tornouse insustentável. Esta representação histórica teria sido incapaz de compreender a relação do fascismo com a sociedade industrial e sua individualidade e impessoalidade, oriunda de um ponto de vista progressista e cientificista. Para dar conta do fascismo, segundo Löwy, é necessária uma concepção histórica destituída das ilusões progressistas, pois o fascismo encontrou espaço para crescer justamente na era do tecnicismo desenfreado e da impessoalidade da sociedade capitalista industrial do século XX. Na Alemanha, o nazismo surgiu com a promessa de um retorno ao passado, a valores de há muito perdidos, crescendo através do desencantamento daqueles que, antes de perderem as esperanças na situação que 
se deu no período entre guerras, já haviam perdido o sentimento de pertencimento e comunitarismo com o advento da industrialização, que no caso alemão se deu a passos largos. Entretanto, embora o nazismo tenha se apresentado como resposta à sociedade industrial, este veio a se mostrar como um regime tão tecnocrata e impessoal quanto aquele que o precedeu.

Acerca das relações entre Benjamin e Schmitt, Löwy considera que nas teses Sobre o conceito de história, Benjamin teria se influenciado pelas ideias da Teologia política de Schmitt, sobretudo pela questão da soberania. Em contrapartida, para Agamben, a Teologia política seria uma resposta de Schmitt à Crítica da violência de Benjamin. Independentemente disto, as três obras possibilitam e se complementam numa interpretação acerca do uso da exceção pelo fascismo, assim como em explicitar os objetivos do "real estado de exceção", a saber: a superação do movimento dialético entre violência instauradora e violência mantenedora do direito, a ruptura com os modelos estatais dirigidos por grupos de poder, que, segundo Benjamin, se dará com o advento da greve geral proletária.

\section{REFERÊNCIAS}

AGAMBEN, G. State of exception. Chicago: The University of Chicago Press, 2005.

. Homo Sacer: o poder soberano e a vida nua I. Tradução de Henrique $\overline{\text { Burigo. }} 2^{\mathrm{a}}$. ed. Belo Horizonte: Editora UFMG, 2010.

BENJAMIN, W. Sobre o conceito de história. In__: LÖWY, M. Walter Benjamin: aviso de incêndio: uma leitura das teses "Sobre o conceito de história". Tradução de Jeanne Marie Gagnebin e Marcos Lutz Müller. São Paulo: Biotempo, 2005. p. 41146.

Para a crítica da violência. In__: BENJAMIN, W. Escritos sobre mito e

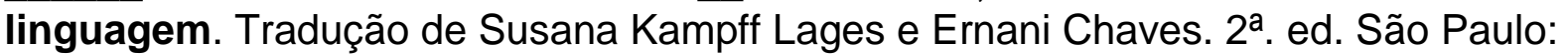
Duas Cidades; Editora 34, 2013. p. 121-156.

LÖWY, M. Walter Benjamin: aviso de incêndio: uma leitura das teses "Sobre o conceito de história”. Tradução de Wanda Nogueira Caldeira Brant. São Paulo: Boitempo, 2005. 
SCHMITT, C. Political theology: four chapters on the concept of sovereignty. Chicago: The University of Chicago Press, 2005. 